\title{
FIBRE REINFORCED GEOPOLYMERS AS INORGANIC STRENGTHENING COMPOSITES FOR MASONRY STRUCTURES
}

\author{
ENRICO GARBIN ${ }^{1 *}$, MATTEO PANIZZA ${ }^{2}$, SERGIO TAMBURINI $^{2}$, \\ MARCO NATALI ${ }^{2}$, AND GILBERTO ARTIOLI ${ }^{3}$ \\ ${ }^{1}$ Inter-Dept. Research Centre for the Study of Cement Materials and Hydraulic Binders (CIRCe) \\ University of Padova, Via G. Gradenigo, 6, 35151 Padova, Italy \\ e-mail: enrico.garbin@unipd.it, http://circe.dicea.unipd.it/ (*corresponding author) \\ ${ }^{2}$ Institute of Condensed Matter Chemistry and Energy Technologies (ICMATE) \\ Italian National Research Council, C.so Stati Uniti, 4, 35127 Padova, Italy \\ email: matteo.panizza@icmate.cnr.it, \{sergio.tamburini, marcostefano.natali\}@cnr.it \\ ${ }^{3}$ Dept. of Geosciences, University of Padova \\ Via G. Gradenigo, 6, 35151 Padova, Italy \\ email: gilberto.artioli@unipd.it
}

Keywords: Geopolymers, Alkali-Activated Materials (AAM), Composite Materials, Strengthening, Masonry structures, FRCM/TRM

\begin{abstract}
The study presents an assessment of externally bonded Fibre-Reinforced GeoPolymers (FRGPS) as strengthening material for masonry structures. Thanks to their tailored chemical and mechanical characteristics, geopolymer matrices can fulfil the restoration criteria for Built Heritage $(B H)$ with the benefit of heat-resistant performances better than those of organic and inorganic matrices used in Externally Bonded FibreReinforced Polymers (EB-FRP) and Fabric-Reinforced Cementitious Matrix (FRCM) materials, respectively. This work is built on the outcomes of a previous investigation that proved the suitability of the developed geopolymer matrix for applications on clay bricks, revealing a good adhesion to masonry substrates and to embedded reinforcements. The behaviour of three FRGPS, including either a bi-directional basalt mesh, a bi-directional carbon mesh or a unidirectional Ultra High Strength Steel (UHSS) fabric, was explored by means of local tests on masonry sub-assemblages made of soft-mud clay bricks and hydraulic lime mortar. In overall, 9 single-lap shear tests on single bricks with a bonded length of $200 \mathrm{~mm}$ and 9 three-point bending tests on 2-brick slices, connected by a mortar joint and reinforced at the bottom face, were carried out. Lastly, the behaviour in alkaline environments of each reinforcement was investigated through tensile tests on coupons immersed for 28 days in alkaline solutions simulating the conditions of the geopolimeric matrices. Results confirmed the interesting potential of FRGPs for strengthening masonry elements, highlighting a good performance of steel and carbon reinforcements. On the other hand, precautions should be taken with basalt meshes that, as expected, were more sensitive to alkaline environments.
\end{abstract}

\section{INTRODUCTION}

Existing masonry buildings and Built Heritage $(\mathrm{BH})$ require a permanent maintenance 
process to withstand the effects of hazardous natural events and mitigate their effects. This can be accomplished by devoted activities of restoration and structural repair adopting traditional and innovative materials and intervention techniques [1-3]. In the last three decades, the use of Externally Bonded Fibre Reinforced Polymers (EB-FRPs) has grown to be one of the reference interventions for existing buildings and for $\mathrm{BH}$ [4-6]. The main advantages of EB-FRPs that fostered their widespread application on existing structures, including also those belonging to the $\mathrm{BH}$, are for instance: their ease and flexibility of application, their fast curing and the related ability in carrying tensile stresses in few hours or days, low weight in comparison to many traditional materials (e.g. steel rods/plates), the high tensile strength and stiffness-to-weight ratio, enhanced fatigue and endurance in aggressive environments [3,5,7]. Nevertheless, FRPs have some compatibility and removability issues with existing and $\mathrm{BH}$ masonry structures, mainly due to the adoption of organic matrices [3,8]. In the last decade, research has investigated the replacement of organic (e.g. epoxy) with inorganic matrices made of cement or lime-based mortars [9-13]. The combination of fibres, usually in the form of meshes, with inorganic matrices is currently often labelled with the acronym of Fibre Reinforced Cementitious Matrix (FRCM) [14,15], acronym that also covers for cement-free matrices, while in several former publications the acronym Textile Reinforced Mortars (TRM) was used $[3,11,13]$. Advantages of FRCMs over FRPs include: better compatibility with masonry substrates and traditional craftsmanship, reversibility, better behaviour under high temperatures and lack of toxic vapours in case of fire, resistance to Ultra-Violet (UV) radiation, water-vapour

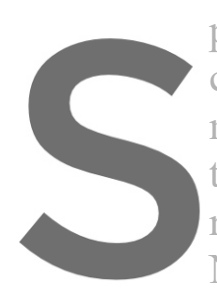
permeability, applicabilit cost $[3,6,8,12,13]$. Mare masonry structures, w to the inherent mecha restoration criteria Nevertheless, traditiona ind

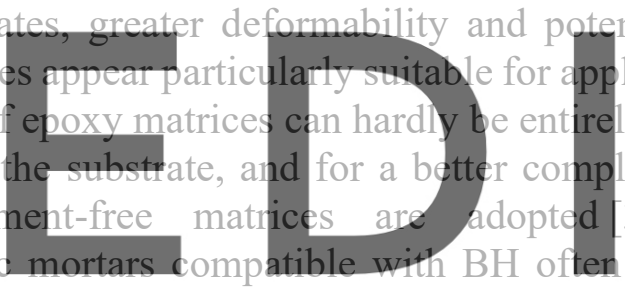

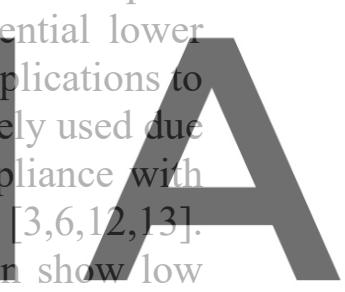
adhesion to masonry substrates and between the FRCM layers [3,6,13]. To overcome this issue,

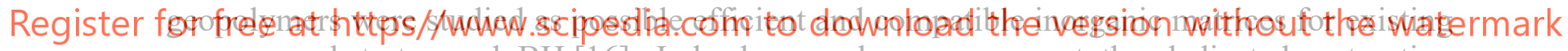
masonry substrates and BH [16]. Indeed, geopolymer can meet the dedicated restoration requirements of $\mathrm{BH}$, thanks to their typical chemical composition and porosity which are similar to that of clay bricks [16], while delivering physico-mechanical performances exceeding those of the best inorganic matrices used in FRCMs [16,17].

Geopolymers are relatively recent and emerging inorganic cement-free binders that present a combination of the best characteristics of ceramic and cement-based materials [16,17]. Moreover, they have a clear advantage over EB-FRPs and FRCMs as non-inflammable and heat-resistant matrices for inorganic composites designed to reach temperatures of $1000^{\circ} \mathrm{C}[16,18]$. Geopolymers are inorganic quasi-fragile materials produced from aluminosilicates typically activated with alkali hydroxide and/or alkali silicate solutions $[16,17]$. Several aluminosilicate or calcium-aluminosilicate raw materials can be used, such as dehydroxylated aluminosilicate clay mineral (e.g. metakaolin) and industrial by-products resulting from high temperature processes such as fly ash or ground blast furnace slag, among others [17]. They are also materials suitable for a greener economy, since they can be derived from by-products or from the recycling of industrial waste materials, and they can be produced with up to ten times lower $\mathrm{CO}_{2}$ emission than Portland cement $[17,19]$. Geopolymer grouts and mortars can be obtained by charging the geopolymer binder with sand or fine 
aggregates [16,17].

Fibre Reinforced GeoPolymer (FRGP) is the combination of a geopolymer grout with fibre meshes or fabrics, similarly to Fibre Reinforced Cementitious Matrix (FRCM) [16]. Several studies were done on geopolymer fibre composites as final product made with both short fibres [20-22] and multiple laminated layers of fabrics [18,23,24], fewer investigations exist on FRGPs for retrofitting structural elements, and most investigations focused on strengthening Reinforced Concrete (RC) beams [25-28]. Whereas, very little contributions on the use of FRGPs as strengthening materials for existing masonry structures are present $[16,29]$. The mechanical models and the design procedures available for FRCMs [14,15,30,31] can be adopted owing to the inherent quasi-fragile behaviour of the geopolymeric matrix. Lastly, for a successful application of FRPs, their durability should be evaluated. Geopolymers have already shown good resistance towards acid and alkaline environments [16,17]. Therefore, the main durability issue is connected to the endurance of the fibres when embedded in a geopolymeric matrix, which provide an alkaline environment that might result corrosive for certain reinforcements as glass or basalt fibres $[32,33]$. Indeed, this is a common issue for the glass fibre laths embedded in lime or cement plasters and for any fibre mesh embedded in the cementitious matrices of FRCMs [34].

In this framework, the behaviour of three FRGPs was explored by means of local tests on masonry sub-assemblages made of soft-mud clay bricks and hydraulic lime mortar. The three FRGPs embedded a bi-directional basalt mesh, a bi-directional carbon mesh and a unidirectional Ultra High Strength Steel (UHSS) fabric, respectively. In total, 9 single-lap shear tests on single bricks with a borded lenth of $200 \mathrm{~mm}$ and 9 three-poin bending tests on 2 -
brick slices, connected by a mortar joint and reinforced at the bottom face, were carried out to
evaluate the bond behaviour and the llexural strengthening performances of the three FR GPs.
Lastly, the behaviour in alkaline environments of each reinforcement y as studied through
tensile tests on coupons immersed for 28 days in alkaline solutions, tentatively simulating the pore solution of the geopolymeric matrices.

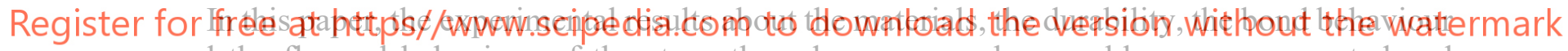
and the flexural behaviour of the strengthened masonry sub-assemblages are presented and discussed. Results confirmed the untapped and interesting potential of FR GPs as strengthening materials, highlighting a good performance of steel and carbon reinforcements. On the other hand, precautions should be taken with un-sized basalt meshes that, as expected, were more sensitive to alkaline environments.

\section{MATERIALS AND METHODS}

Low-strength $250 \times 120 \times 55 \mathrm{~mm}^{3}$ soft mud clay bricks, intended to simulate a typical historical masonry unit, were adopted. Their average performance (coefficient of variation $\mathrm{CoV}$ - in brackets) was $17.7 \mathrm{~N} / \mathrm{mm}^{2}(6.2 \%)$ in compression and $4.43 \mathrm{~N} / \mathrm{mm}^{2}(10.3 \%)$ in bending [35], whereas their apparent density was $1.63 \cdot 10^{3} \mathrm{~kg} / \mathrm{m}^{3}(1.0 \%)$.

The mortar forming the joint of the 2-brick slice bending specimens was a commercially available pre-mixed cement-free pozzolana lime mortar with siliceous sand aggregates, category M15 according to Eurocode 6 [36], with a 28-day average strength of $14.7 \mathrm{~N} / \mathrm{mm}^{2}$ (2.5\%) measured according to standard EN 1015-11 [37].

The geopolymer matrix, extensively described in [16], was prepared with metakaolin and 
ground granulated furnace slag as solid precursors, and sodium silicate with molar ratio $\mathrm{SiO}_{2} / \mathrm{Na}_{2} \mathrm{O}$ of 1.5 and concentration of $41.3 \%$ as liquid activator. The binder embedded fine siliceous sand and wollastonite as inorganic aggregates, resulting in a grout with density of $2.0 \cdot 10^{3} \mathrm{~kg} / \mathrm{m}^{3}(1.0 \%)$, after hardening. The cylinder compressive strength was $44.6 \mathrm{~N} / \mathrm{mm}^{2}$ $(3.0 \%)$ and the splitting resistance was $4.4 \mathrm{~N} / \mathrm{mm}^{2}(7.1 \%)$ in average, measured on cylindrical specimens with diameter of $35 \mathrm{~mm}$ and aspect ratio of 2 .

The geopolymer matrix was coupled with 3 types of fibre reinforcements, either a unidirectional steel fabric or two balanced bidirectional fibre meshes, i.e. carbon or basalt, thus generating three Fibre-Reinforced GeoPolymers (FRGP).

The unidirectional steel fabric (STL) was composed by Ultra High Strength Steel (UHSS) strands, mounted on a mesh support, approximately $6 \mathrm{~mm}$ spaced apart. The datasheet reports a characteristic tensile strength of $3070 \mathrm{~N} / \mathrm{mm}^{2}$, an average elastic modulus of $190 \cdot 10^{3} \mathrm{~N} / \mathrm{mm}^{2}$ and an equivalent thickness of $0.075 \mathrm{~mm}$.

The carbon reinforcement (CAR) was a bidirectional balanced mesh made of uncoated yarns, having a centre-to-centre spacing of about $9 \mathrm{~mm}$, with a surface density of $200 \mathrm{~g} / \mathrm{m}^{2}$. It has a characteristic tensile strength of $2500 \mathrm{~N} / \mathrm{mm}^{2}$, an average elastic modulus of $230 \cdot 10^{3} \mathrm{~N} / \mathrm{mm}^{2}$ and an equivalent thickness of $0.048 \mathrm{~mm}$, according to its technical datasheet.

The basalt reinforcement (BAS) was a bidirectional balanced mesh made of un-sized yarns, having a centre-to-centre spacing of about $8 \mathrm{~mm}$, with a surface density of $300 \mathrm{~g} / \mathrm{m}^{2}$. It has a characteristic tensile strength of $1735 \mathrm{~N} / \mathrm{mm}^{2}$, an average elastic modulus of $90 \cdot 10^{3} \mathrm{~N} / \mathrm{mm}^{2}$ and an equivalent thickness

\section{The experimental} tensile tests carried out conditioning in 3 differt longitudinally applied to made of 2-brick slices
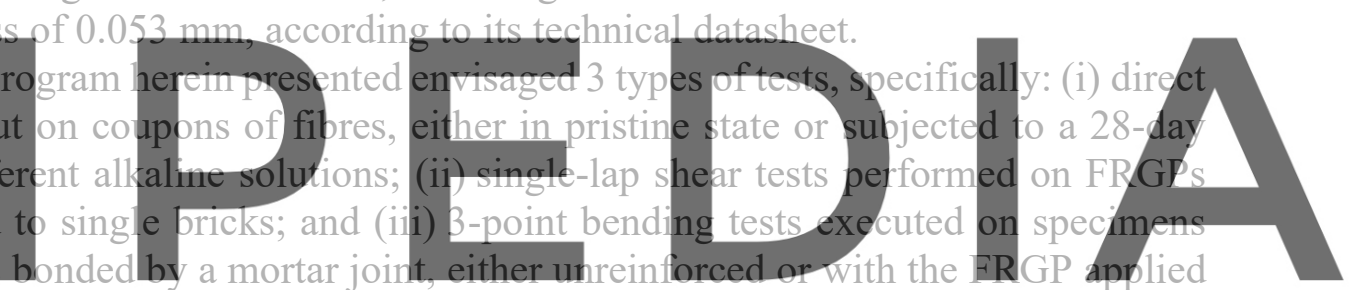
to the bottom surface.

Register for free at https//www.scipedia.com to download the version without the watermark 2.1 Tensille tests on fabric coupons

Either singie strand, in the case of steel, or 2-yans coupons, in the case of carbon and basalt, were tested in tension in a $25 \mathrm{kN}$ electro-mechanic universal machine. Specimens were $380 \mathrm{~mm}$ long to allow a free length of about $280 \mathrm{~mm}$ after the application at each end of 2 aluminium tabs (or sleeves in the case of steel) $50 \mathrm{~mm}$ long, glued with epoxy resin, which were clamped by the test machine. Carbon and basalt yarns were impregnated with a small amount of epoxy resin to load uniformly the yarns and obtaining the full resistance of the mesh, thus preventing or limiting possible uneven distribution of stresses inside the reinforcement.

Tests were carried out either on pristine samples of reinforcements ( $\mathrm{C} 0$ condition) or on fibres immersed for 28 days in 3 alkaline solutions to investigate their possible degradation in environments simulating the possible pore solution of the geopolymer matrix. $\mathrm{C} 1$ consisted in a $5 \%$ aqueous solution of $\mathrm{NaOH}$ (corresponding to $1.25 \mathrm{M}$ ), as provided by the standard ASTM E2098/E2098M [38]. Aqueous solutions of either sodium (the same used as binder activator) or potassium silicate were adopted for $\mathrm{C} 2$ and $\mathrm{C} 3$. The formulation of the potassium silicate had a molar ratio $\mathrm{SiO}_{2} / \mathrm{K}_{2} \mathrm{O} \sim 1.5$, equal to the silica/sodium one, with a solid matter concentration of $46.0 \%$. Silicates were dissolved in water to achieve the same concentration of 
$\mathrm{Na}$ (or K) atoms of the $\mathrm{C} 1$ solution. At least 4 samples for each type of reinforcement and conditioning solution were tested. After the immersion, fibres were rinsed and dried to measure the weight loss by means of an analytical balance.

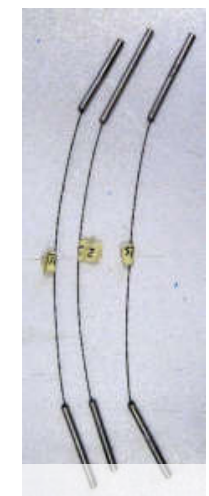

(a)

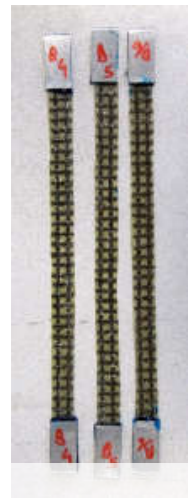

(b)

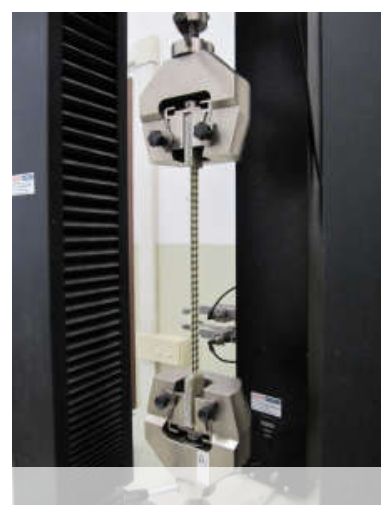

(c)

Figure 1: Samples of steel (a) and basalt (b) reinforcement for tensile tests, and a coupon ready for testing (c)

\subsection{Single-lap shear tests}

Specimens consisted in a single brick with the FRGP applied longitudinally onto the wider surface (Fig. 2a) with a bonded area $200 \mathrm{~mm}$ long and $60 \mathrm{~mm}$ wide, delimited by masking tape

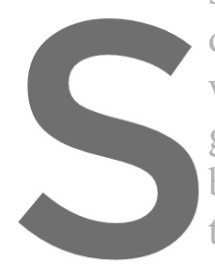

during casting. A protru

was used for the connecti

geopolymer matrix for

beyond the edge of the brick.

the FRGP included eithe 8
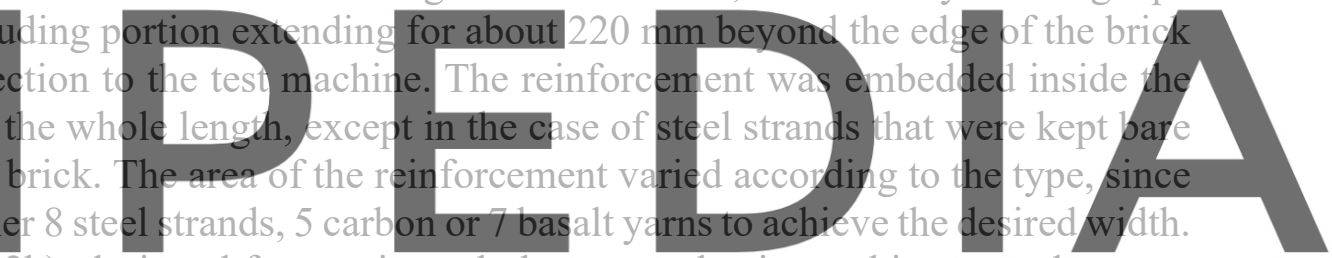

The test setup (Fig. 2b), designed for a universal electro-mechanic machine, was the same

Register for free ath hted in syveral former researches [6,39]. It Gonsisted in two steel plates 50 mm thick connected by 4 threaded bars, two of which lastened to the bottom head of the test machine.

The specimen was inserted between those plates, taking care to alignments and contacts, and the protruding reinforcement was glued with quick setting resin to a steel part connected to the upper head of the test machine by means of a ball joint. Four potentiometers were used to monitor displacements, two positioned at the beginning of the bonded length, one in the middle and one at the unloaded end of the FRGP. Tests were carried out in displacement control, with a rate of the movable loading beam progressively incremented from $0.3 \mathrm{~mm} / \mathrm{min}$ to $1.2 \mathrm{~mm} / \mathrm{min}$ in the last stages of the tests. Load and displacement values were recorded by an external acquisition system at $10 \mathrm{~Hz}$.

Three specimens per type of reinforcement were tested, for overall of 9 samples.

\subsection{Bending tests on 2-brick specimens}

Three-point bending tests were carried out on specimens made of 2 slices, about $32 \mathrm{~mm}$ thick, cut from single bricks. Those slices were longitudinally aligned and connected by a $10 \mathrm{~mm}$ mortar joint, thus obtaining samples approximately $510 \mathrm{~mm}$ long (Fig. 3a). Subsequently, the FRGP was centrally applied to the bottom side, extending for about $330 \mathrm{~mm}$. The reinforcement comprised 3 strands or yarns for each type of fibre. The geometry of the 
specimens was a trade-off between representativeness and materials availability.

A $50 \mathrm{kN}$ electro-mechanic universal machine equipped with a commercial setup for bending (Fig. 3) was used. The span between the bottom supports was $380 \mathrm{~mm}$, slightly greater than the length of the FRGP. Contacts between sample and steel supports were improved by small rubber inserts. Tests were carried out in displacement control, with a rate of the movable loading beam of $0.5 \mathrm{~mm} / \mathrm{min}$. Load and displacements were recorded by the embedded data acquisition of the universal machine.

Three specimens per type of reinforcement were tested, for overall 9 samples. In addition, 3 unreinforced specimens were tested twice at $0.1 \mathrm{~mm} / \mathrm{min}$ with a $2.5 \mathrm{kN}$ load cell, repairing the failed joint with epoxy resin and testing again the same specimen to measure also the resistance of the strongest mortar-to-brick interface.

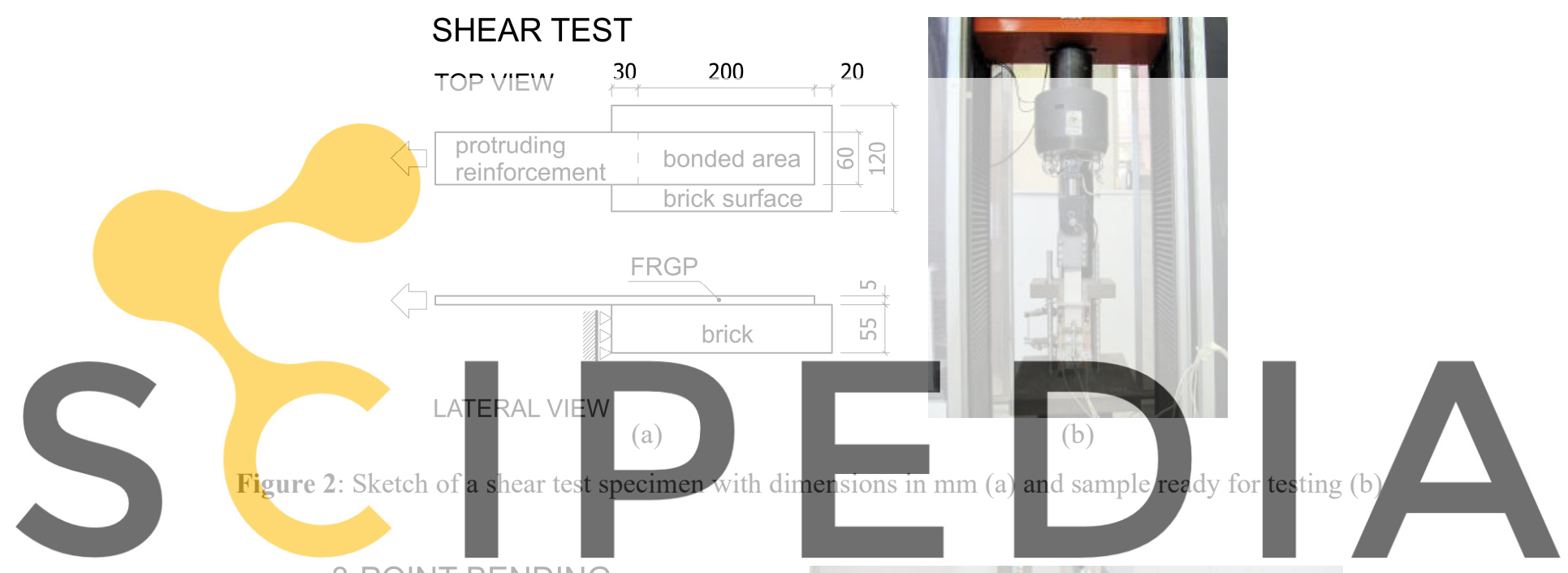

3-POINT BENDING

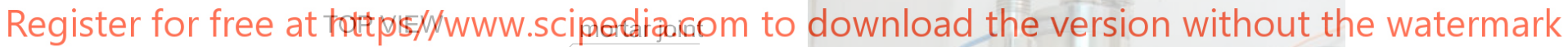

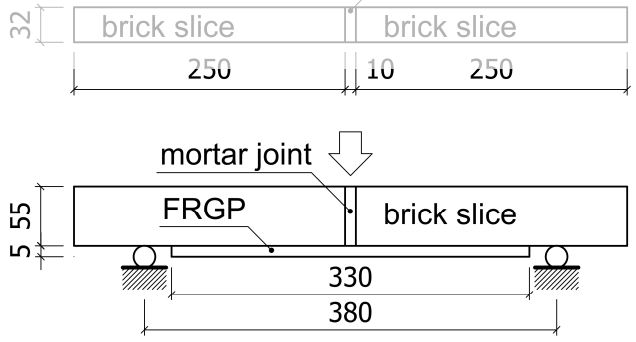

LATERAL VIEW

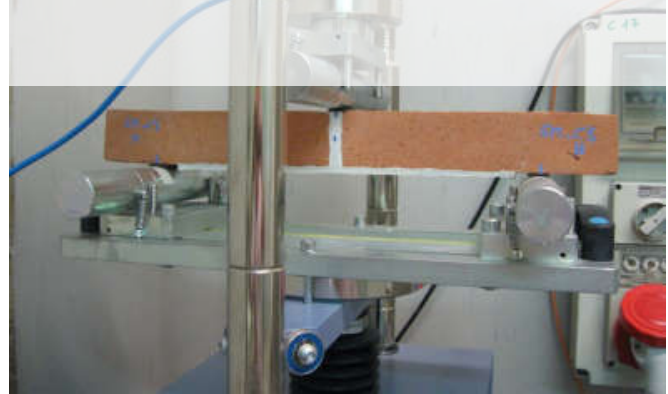

(b)

Figure 3: Sketch of a 3-point bending specimen, with dimensions in mm (a) and sample ready for testing (b)

\section{RESULTS AND DISCUSSION}

\subsection{Tensile tests on fabric coupons}

Failure was generally as expected, with a fibre tensile rupture localised inside the free length between the anchoring, in some cases close to the tabs. Although few specimens showed an 
irregular failure, due to slippage problems at the connection with the test machine or to an imperfect alignment, at least 4 suitable results were included in calculations.

The average tensile strengths $f_{t, a v g}$, grouped by fibre and conditioning type, are listed in Table 1 together with their coefficient of variation $(\mathrm{CoV})$. Measured values of weight loss are shown in Figure 4a, whereas tensile strength retentions are shown in Figure 4b.

Steel strands were substantially not affected by the alkaline environment, with a strength loss always lower than 3\% that can be considered within a common experimental variability, despite a weight loss that exceeded 3\% in two cases, probably due to the loss of the protecting coating without impairing the resisting cross-section. Carbon fibres presented a strength retention of about $93 \%$ in sodium hydroxide and sodium silicate solutions and were slightly more sensitive to potassium silicate solutions as proved by a lower strength retention of about $86 \%$. Conversely, they showed the lowest values of weight loss of about $0.2-0.3 \%$. Finally, as expected, the un-sized basal fibres showed the worst degradation, with a strength loss of about $25 \%$ in silicate solutions and $45 \%$ in sodium hydroxide solution, with a weight loss comprised between $0.7-1.9 \%$ (the lowest was measured in $\mathrm{NaOH}$ ). Strength conversion coefficients for aggressive environments proposed by the Italian guidelines CNR DT200R1 [40] (0.85 for carbon and 0.50 for glass fibres) and CNR DT215 [15] (0.70 regardless of the fibres type), compared to the present experimental results, appear reasonably close where applicable. As observed in [32], there is no apparent correlation between weight loss and strength retention.

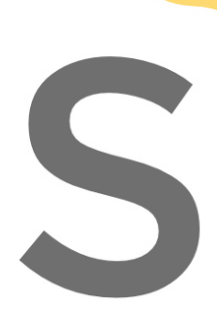

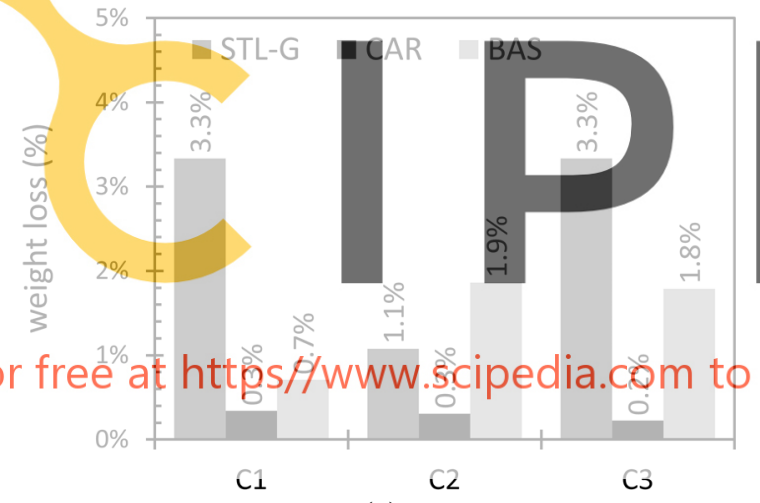

(a)

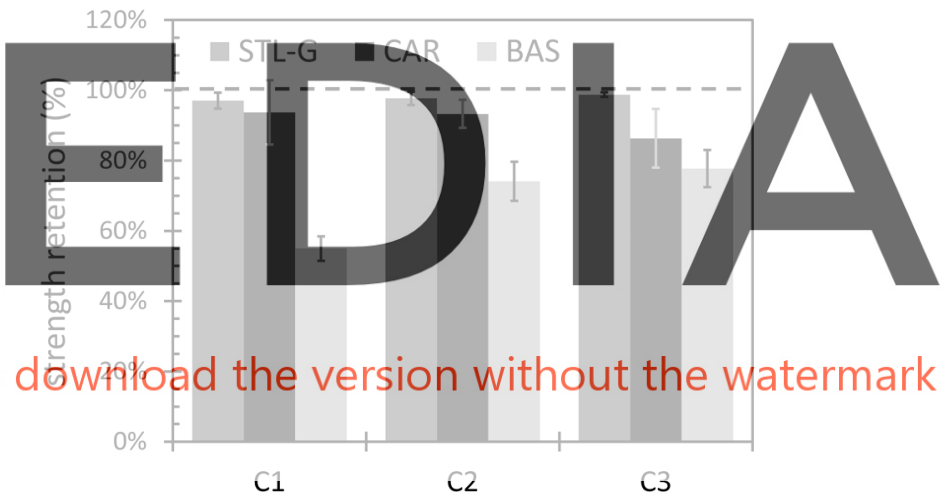

(b)

Figure 4: Weight loss (a) and tensile strength retention (b) measured on conditioned fibres

Table 1: average tensile strength in pristine condition $(\mathrm{C} 0)$ and after treatment in alkalis, with $\mathrm{CoV}$ in brackets

\begin{tabular}{|c|c|c|c|c|}
\hline Specimen & $\begin{array}{c}\mathbf{C 0}-\mathbf{f}_{\text {t,avg }} \\
\mathbf{N} / \mathbf{m m}^{2}\end{array}$ & $\begin{array}{c}\mathbf{C 1}-\mathbf{f}_{\text {t,avg }} \\
\mathbf{N} / \mathbf{m m}^{2}\end{array}$ & $\begin{array}{c}\mathbf{C 2}-\mathbf{f}_{\text {t,avg }} \\
\mathbf{N} / \mathbf{m m}^{2}\end{array}$ & $\begin{array}{c}\mathbf{C 3}-\mathbf{f}_{\text {t,avg }} \\
\mathbf{N} / \mathbf{m m}^{\mathbf{2}}\end{array}$ \\
\hline STL & $3125(0.5 \%)$ & $3033(2.4 \%)$ & $3053(1.9 \%)$ & $3086(0.7 \%)$ \\
\hline CAR & $2854(7.9 \%)$ & $2675(9.7 \%)$ & $2663(4.3 \%)$ & $2464(9.7 \%)$ \\
\hline BAS & $1845(3.2 \%)$ & $1013(6.3 \%)$ & $1367(7.5 \%)$ & $1434(6.8 \%)$ \\
\hline
\end{tabular}

\subsection{Single-lap shear tests}

Failures were substantially different for each type of FRGP. Steel strands failed in tension in 2 specimens (Fig. 5a), while in one case a partial debonding, about $2 / 3$ of the bonded length, occurred (Fig. 5b). Carbon yarns generally slipped inside the matrix (Fig. 5c), with minor signs 
of tensile failure in the most external fibrils and several cracks in the protruding FRGP, about 25-30 mm spaced apart. On the other hand, basalt yarns showed a rather clear tensile rupture with no remarkable sign of slippage (Fig. 5d).

Results, in terms of failure mode, maximum load $P_{\max }$ and maximum stress $\sigma_{\max }$, are given in Table 2, together with the exploitation coefficient $\eta_{S T}$ calculated as the ratio of $\sigma_{\max }$ and the fibre tensile strength $f_{t, \text { avg }}$ measured in pristine conditions $(\mathrm{C} 0)$. As expected, the effectiveness of the FRGP was in all cases lower than 1, confirming that shear tests, although excluding bond failures, cannot achieve the reference strength of the fibre reinforcements when embedded in inorganic matrices. Nonetheless, in the case of steel, the exploitation was not lower than 0.8 , thus suggesting that steel strands are less sensitive to this type of test. Carbon fibres slipped at values comprised between 0.41 and 0.47 , while basalt failed at 0.23 and 0.32 , cracked specimen excluded. Similar exploitation coefficient $\eta_{S T}$ are currently obtained for optimal FRCM systems $[6,12,13,34]$.

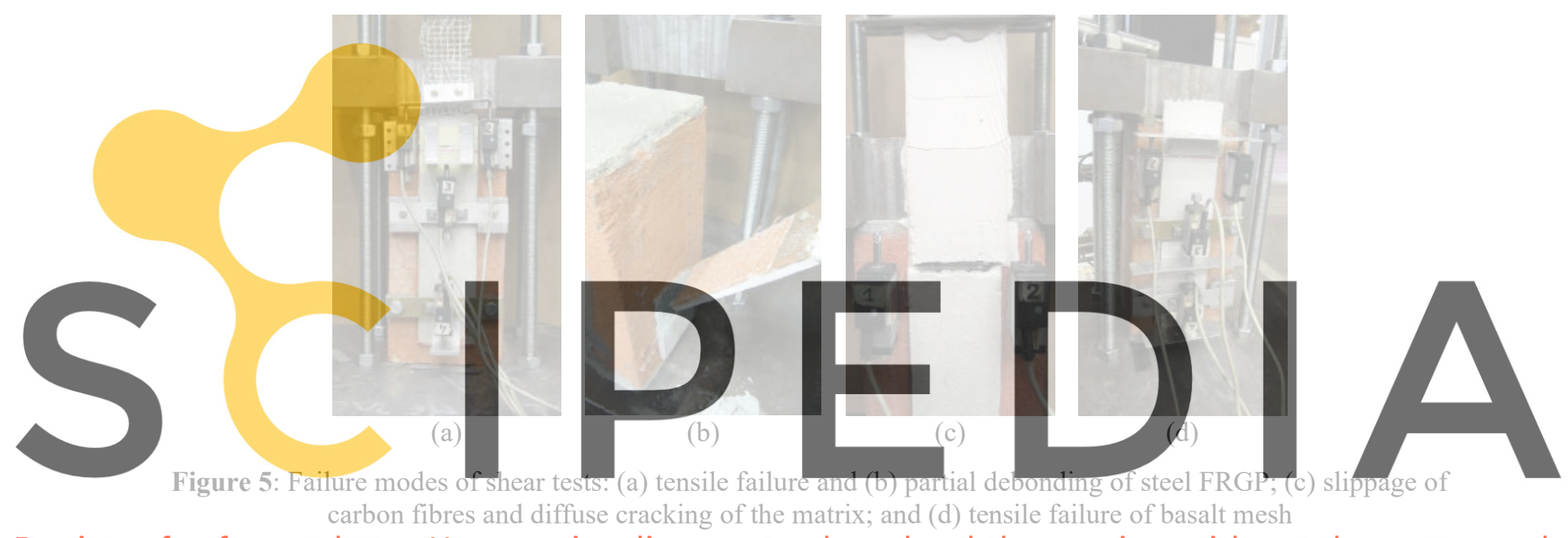

Register for free at https//www.scipedia.com to download the version without the watermark

Table 2: results of single-lap shear tests

\begin{tabular}{|c|c|c|c|c|}
\hline Specimen & Main failure & $\mathbf{P}_{\max }$ & $\begin{array}{c}\sigma_{\max } \\
\mathbf{N} / \mathbf{m m}^{2}\end{array}$ & $\eta_{\mathrm{ST}}$ \\
\hline ST-STL-1 & tensile break & 12764 & 2966 & 0.95 \\
\hline ST-STL-2 & debonding & 9214 & 2141 & 0.69 \\
\hline ST-STL-3 & tensile break & 10678 & 2481 & 0.79 \\
\hline ST-CAR-1 & tensile break/slippage & 3271 & 1140 & 0.44 \\
\hline ST-CAR-2 & tensile break/slippage & 3480 & 1213 & 0.47 \\
\hline ST-CAR-3 & tensile break/slippage & 3030 & 1057 & 0.41 \\
\hline ST-BAS-1 & tensile break $(*)$ & 804 & 271 & 0.15 \\
\hline ST-BAS-2 & tensile break & 1285 & 433 & 0.23 \\
\hline ST-BAS-3 & tensile break & 1737 & 585 & 0.32 \\
\hline
\end{tabular}

\subsection{Bending tests on 2-brick specimens}

The failure of the 3 unreinforced specimens was always located at the mortar-brick interface (Fig 5a). They were tested twice, the second time after repair of the failed joint, and showed a 
remarkably variable resistance comprised between 37 and $129 \mathrm{~N}$, corresponding to a bond strength, calculated as the ratio of maximum bending moment and section modulus, comprised between 0.22 and $0.81 \mathrm{~N} / \mathrm{mm}^{2}$. The average strength of the weakest joint of each specimen was $0.41 \mathrm{~N} / \mathrm{mm}^{2}$, while the average of the strongest ones was $0.62 \mathrm{~N} / \mathrm{mm}^{2}$.

In the case of steel FRGP, failure was due to a shear crack of the brick that started close to the end of the reinforcement (Fig 5b), after a wedge-like cracking of the portion beneath the applied load. Carbon FRGP failed due to slippage of the fibres (Fig 5c), whereas basalt FRGP broke in tension (Fig 5d), in all cases in correspondence of the main crack that opened at the mortar-brick interface.

Results are listed in Table 3 in terms of failure mode, maximum load $P_{\max }$ and maximum stress $\sigma_{\max . s b}$, the latter calculated through a section analysis based on the assumption of a stressblock $0.8 \cdot x$ high, being $x$ the neutral axis depth. The exploitation coefficient $\eta_{B T}$ was calculated similarly to the case of $\eta_{S T}$. Steel-reinforced specimens could not attain a fibre effectiveness close to shear test samples, due to the earlier shear failure of the brick. In the case of carbon FRGP, which also showed one shear failure mode, the exploitation $\eta_{B T}$ of $0.41-0.44$ was comparable to $\eta S T$. Conversely, basalt FRGP reached relatively high values of $\eta_{B T}(0.60$ and 0.71), more than twice the $\eta_{S T}$ of ST-BAS-2 and ST-BAS-3, probably thanks to the reduced number of yarns and to the bending specimen that allowed an evener stress distribution. Similar exploitation coefficient $\eta_{B T}$ are currently obtained for optimal FRCM systems $[6,10,13,34]$.
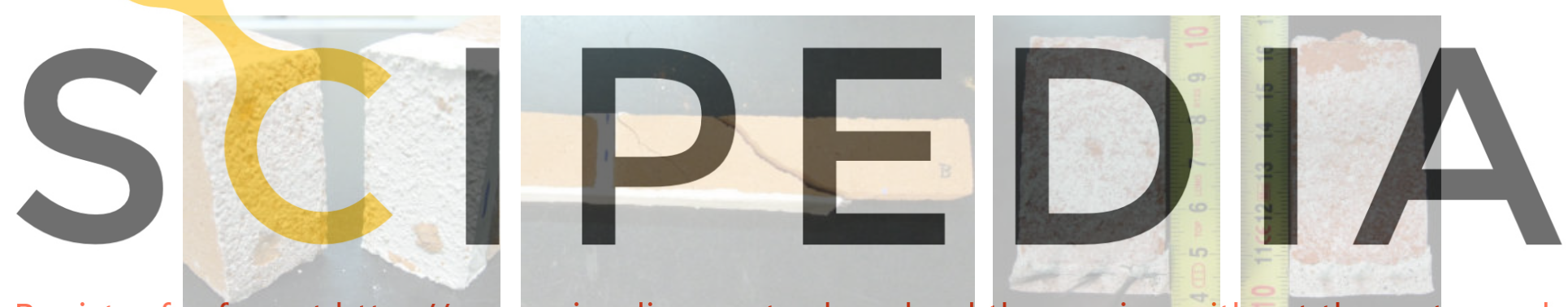

Register for free at(dttps//www.scipedia.com to download the version without the watermark

Figure 5: Failure modes of bending tests: (a) joint failure of unreinforced specimens; (b) brick shear failure in case of steel FRPG; (c) slippage and partial rupture of carbon fibres; and (d) tensile failure of basalt mesh

Table 3: Results of 3-point bending tests

\begin{tabular}{|r|l|r|r|l|}
\hline Specimen & \multicolumn{1}{|c|}{ Failure } & $\begin{array}{c}\mathbf{P}_{\max } \\
\mathbf{N}\end{array}$ & $\begin{array}{c}\boldsymbol{\sigma}_{\mathbf{m a x}, \mathbf{s b}} \\
\mathbf{N} / \mathbf{m m}^{2}\end{array}$ & $\boldsymbol{\eta}_{\mathbf{B T}}$ \\
\hline BT-STL-1 & brick shear & 1289 & 1591 & 0.49 \\
\hline BT-STL-2 & brick shear & 1425 & 1799 & 0.56 \\
\hline BT-STL-3 & brick shear & 1515 & 1919 & 0.59 \\
\hline BT-CAR-1 & slippage & 1218 & 1257 & 0.44 \\
\hline BT-CAR-2 & slippage & 1119 & 1170 & 0.41 \\
\hline BT-CAR-3 & slippage / brick shear & 1199 & 1258 & 0.44 \\
\hline BT-BAS-1 & tensile break $(*)$ & 321 & 434 & 0.24 \\
\hline BT-BAS-2 & tensile break & 798 & 1114 & 0.60 \\
\hline BT-BAS-3 & tensile break & 927 & 1302 & 0.71 \\
\hline
\end{tabular}




\section{CONCLUSIONS}

The paper presented an assessment of the adhesion and durability properties of FRGPs as strengthening material for masonry buildings. The FRGPs were made of an eco-efficient and heat-resistant geopolymeric matrix that has a chemical composition and porosity similar to that of soft-mud clay bricks simulating a typical historical masonry unit. Therefore, the matrix is an interesting inorganic bonding agent for the implementation of removable and compatible composites suitable, not only for exiting masonry buildings, but also for BH. The three FRGPs studied were reinforced either with a bi-directional balanced basalt mesh, a bi-directional balanced carbon mesh or a unidirectional UHSS fabric.

The adhesion and mechanical performances of the three FRGPs were investigated by means of local 9 single-lap shear tests on single bricks with a bonded length of $200 \mathrm{~mm}$ and 9 threepoint bending tests on two brick slices, connected by a mortar joint and reinforced at the bottom face. The exploitation coefficients derived from the shear and the bending tests are in accordance with the best performances currently obtained by the FRCMs. Nonetheless, FRGPs are provided with an undoubtedly more innovative inorganic matrix.

On the other hand, further studies are necessary to investigate the durability of the FRGPs. In fact, the behaviour in alkaline environments simulating the pore solution of the geopolymeric matrices highlighted the possibility of undesired corrosive outcomes on the fibres, especially when they are un-sized (or they lost part of the sizing) as the basalt mesh used in this paper.

The results confirmed the untapped and interesting potential of FRGPs. In particular, The

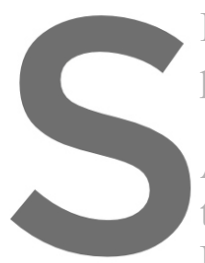
FRGPS reinforced. with the carbon mesh and the UHSS fabrit
potential inorganic composites suitable for strengthening exiting
Acknowledgements. Several industries provided free of charge
this research: Fidia s.r.1. (Perugia, Italy) the basalt mesh, Kera Ultra High Strength Steel fabric, BASF CC alia (Treviso,
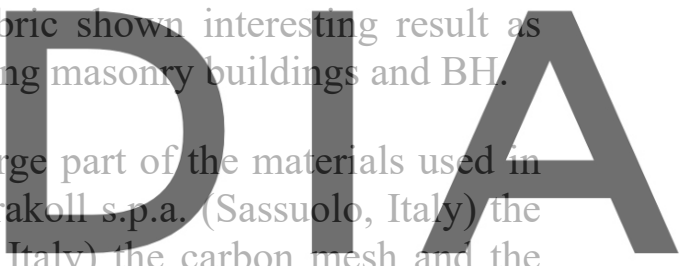

pozzolana lime mortar, San Marco Terreal Italia (Noale, Italy) the soft mud clay bricks.

Register for free at https//www.scipedia.com to download the version without the watermark REFERENCES

[1] Modena, C., Valluzzi, M.R., da Porto, F., Casarin, F. Structural Aspects of the Conservation of Historic Masonry Constructions in Seismic Areas: Remedial Measures and Emergency Actions. Int. J. Archit. Herit. (2011) 5(4-5):539-558.

[2] Tomaževič, M. Seismic Resistance of Masonry Buildings in Historic Urban and Rural Nuclei: Lessons Learned in Slovenia. International Journal of Architectural Heritage, Int. J. Archit. Herit. (2011) 5(4-5):436-465.

[3] Valluzzi, M.R., Modena, C., de Felice, G. Current Practice and Open Issues in Strengthening Historical Buildings with Composites. Mater. Struct. (2014) 47(12):1971-1985.

[4] Triantafillou, T.C. Strengthening of Masonry Structures Using Epoxy-Bonded FRP Laminates. J. Compos. Constr. (1998) 2(2):96-104.

[5] Shrive, N.G. The Use of Fibre Reinforced Polymers to Improve Seismic Resistance of Masonry. Constr. Build. Mater. (2006) 20(4):269-277.

[6] Garbin, E., Panizza, M., Valluzzi, M.R. Experimental Characterization of Glass and Carbon FRCMs for Masonry Retrofitting. ACI Special Publication, 324:3.1-3.20. American Concrete Institute (2018).

[7] Hollaway, L.C. A Review of the Present and Future Utilisation of FRP Composites in the Civil 
Infrastructure with Reference to Their Important In-service Properties. Constr. Build. Mater. (2010) 24(12):2419-2445.

[8] Tedeschi C., Kwiecien A., Valluzzi M.R., Zajac B., Garbin E., Binda L. Effect of thermal ageing and salt decay on bond between FRP and masonry. Mater. Struct. (2014) 47(12):20512065.

[9] Papanicolaou, C.G., Triantafillou, T.C., Karlos, K., Papathanasiou, M. Textile-Reinforced Mortar (TRM) Versus FRP as Strengthening Material of URM Walls: In-plane Cyclic Loading. Mater. Struct. (2007) 40(10): 1081-1097.

[10] Papanicolaou, C.G., Triantafillou, T.C., Papathanasiou, M., Karlos, K. Textile Reinforced Mortar (TRM) Versus FRP as Strengthening Material of URM Walls: Out-of-plane Cyclic Loading. Mater. Struct. (2008) 41(1):143-157.

[11] Garmendia, L., Marcos, I., Garbin E., Valluzzi, M.R. Strengthening of Masonry Arches with Textile-Reinforced Mortar: Experimental Behaviour and Analytical Approaches. Mater. Struct. (2014) 47(12):2067-2080.

[12] de Felice, G., De Santis, S., Garmendia, L., Ghiassi, G., Larrinaga, P., Lourenço, P.B., Oliveira, D.V., Paolacci, F. and Papanicolaou C.G. Mortar-based systems for externally bonded strengthening of masonry. Mater. Struct. (2014), 47(12):2021-2037.

[13] Kouris L.A.S. and Triantafillou T.C. State-of-the-art on strengthening of masonry structures with textile reinforced mortar (TRM). Constr. Build. Mater. (2018) 188:1221-1233.

[14] ACI 549.4R-13. Guide to Design and Construction of Externally Bonded FRCM Systems for Repair and Strengthening Concrete and Masonry Structures. American Concrete Institute (2013).

[15] CNR DT 215/2018. Guide for the Design and Construction of Externally Bonded Fibre Reinforced Inorganic Matrix Systems for Strengthening Existing Structures. Italian National Research Council (2020).

[16] Tamburini, S., Natali, M., Garbin, E., Panizza, M., Favaro, M. and Valluzzi, M.R. Geopolymer matrix for fibre reinforced composites aimed at strengthening masonry structures. Constr. Build. Mater. (2017) 141:542-552.

[17] Provis, L. and van Deventer J.S.J. Geopolymers: Structure, processing and industrial applications. Woodhead Publishing in Materials (2009).

[18] Kurz, S., Balaguru, P.N. Comparison of Inorganic and Organic Matrices for Strengthening of RC Beams with Carbon Sheets. J. Struct. Eng.-ASCE (2001) 127(1):35-42.

[19] Pacheco-Torgal, F. and Jalali S. Eco-Efficient Construction and Building Materials. Springer Science+Business Media (2011).

[20] Shaikh, F.U.A. Review of mechanical properties of short fibre reinforced geopolymer composites. Constr. Build. Mater. (2013) 43:37-49.

[21] Welter, M., Schmücker, M., MacKenzie, K.J.D. Evolution of the fibre-matrix interactions in basalt-fibre-reinforced geopolymer-matrix composites after heating, J. Ceram. Sci. Technol. (2015) 6(1):17-24.

[22] Vickers, L., van Riessen, A., Rickard, W.D.A. Fire-resistant Geopolymers: Role of fibres and fillers to enhance thermal properties. Springer Briefs in Materials (2015).

[23] Toutanji, H., Deng, Y. Comparison between organic and inorganic matrices for RC beams strengthened with carbon fiber sheets, J. Compos. Constr.-ASCE (2007) 11(5):507-513.

[24] Ferone, C., Colangelo, F., Roviello, G., Asprone, D., Menna, D., Balsamo, A., Prota, A., Cioffi, R., Manfredi, G. Application-oriented chemical optimization of a metakaolin based geopolymer. Materials (2013) 6(5):1920-1939.

[25] Papakonstantinou, C.G., Katakalos, K. Flexural behavior of reinforced concrete beams 
strengthened with a hybrid inorganic matrix-steel fibre retrofit system, Struct. Eng. Mech. (2009) 31(5):567-585

[26] Menna, C., Asprone, D., Ferone, C., Colangelo, F., Balsamo, A., Prota, A., Cioffi, R., Manfredi, G. Use of geopolymers for composite external reinforcement of RC members, Compos Part B-Eng (2013) 45(1):1667-1676.

[27] Katakalos, K., Papakonstantinou, C.G. Fatigue of reinforced concrete beams strengthened with steel-reinforced inorganic polymers, J. Compos. Constr.-ASCE (2009) 13(2):103-112.

[28] Carabba, L., Santandrea, M., Carloni, C., Manzi, S., Bignozzi, M.C. Steel fiber reinforced geopolymer matrix (S-FRGM) composites applied to reinforced concrete structures for strengthening applications: A preliminary study. Compos Part B-Eng (2017) 128:83-90.

[29] Garbin, E., Panizza, M., Valluzzi, M.R., Nardon, F., Tamburini, S., Favaro, M., Magro, A., Characterization of Fibre Reinforced Geopolymers as structural strengthening material for historical brick masonry. In: Proc. of $9^{\text {th }}$ International Masonry Conference, Guimarães, Portugal, July 7-9 (2014).

[30] Ceroni, F. and Salzano, P. Design provisions for FRCM systems bonded to concrete and masonry elements. Compos Part B-Eng (2018) 143:230-242.

[31] Meriggi, P., de Felice, G., De Santis, S. Design of the out-of-plane strengthening of masonry walls with fabric reinforced cementitious matrix composites. Constr. Build. Mater. (2020) 240: 117946, https://doi.org/10.1016/j.conbuildmat.2019.117946

[32] Tamburini, S., Natali, M., Garbin, E., Valluzzi, M.R., Artioli, G. Comparison of fibres in geopolymer matrix for structural reinforcement of masonry (FRGP): Compatibility, reactivity, durability. In: ECI Conference on Geopolymers: The route to eliminate waste and emissions in ceramic and cement manufacturing, Schloss Hernstein (Austria), May 24-29 (2015).

[33] Dhand, V., Mittal, G., Rhee, K.Y., Hui, D. A short review on basalt fiber reinforced polymer composites. Compos Part B-Eng (2015) 73:166-180.

[34] Triantafillou, T. Textile Fibre Composites in Civil Engineering. Woodhead Publishing Series in Civil and Structural Engineering (2016).

[35] Girardello, P. Rinforzo di volte in muratura con materiali compositi innovativi. Ph.D. Thesis, University of Padova, Italy (2013). In Italian.

[36] EN 1996-1-1. Eurocode 6: Design of masonry structures - General rules for reinforced and unreinforced masonry structures. European Committee for Standardization (2005).

[37] EN 1015-11. Methods of test for mortar for masonry. Determination of flexural and compressive strength of hardened mortar. European Committee for Standardization (2019).

[38] ASTM Standard E2098/E2098M-13. Standard Test Method for Determining Tensile Breaking Strength of Glass Fiber Reinforcing Mesh for Use in Class PB Exterior Insulation and Finish Systems (EIFS), after Exposure to a Sodium Hydroxide Solution. ASTM International, West Conshohocken, PA (2013).

[39] Panizza, M., Garbin, E., Valluzzi, M.R., Modena, C. Experimental comparison of various types of specimens subjected to SL and DL shear bond tests on EB composites applied to bricks. In: $6^{\text {th }}$ Int. Conf. on FRP Composites in Civil Engineering - CICE 2012, Rome (Italy), June 13-15 (2012).

[40] CNR DT 200R1/2013. Guide for the Design and Construction of Externally Bonded FRP Systems for Strengthening Existing Structures. Italian National Research Council (2013). 